\title{
SPECIAL GUEST REVIEW Color Selection and Reproduction in Dentistry. Part 1: Fundamentals of Color
}

Selección de color y reproducción en Odontología Parte 1: Fundamentos de color

Knowing the optical phenomena that determine the chromatic expression of tooth tissues and their clinical application are essential factors for obtaining esthetic excellence in restorative treatments. Tooth color matching with restorative materials is influenced by several factors, which can produce frustrating results, for both the professional and the patient, when they are not controlled. Based on scientific evidence, a sequence of three articles were performed describing the fundamentals of color formation, the characteristics of the light interaction with the dental tissues and restorative materials and the main methods of color selection and reproduction in esthetic dentistry.

\section{KEYWORDS}

Color vision; Chroma; Hue; Value; Light; Shade; Esthetic Dentistry.

\section{RESUMEN}

El conocimiento de los fenómenos ópticos que determinan la expresión cromática de los tejidos dentales y su aplicación clínica son factores esenciales para la obtención de la excelencia estética. La escogencia de color de los diversos materiales de restauración está influenciada por varios factores, los cuales pueden producir resultados frustrantes, tanto para el profesional como para el paciente cuando no se loran resultados satisfactorios. Basados en evidencia científica, se establece una serie de tres artículos los cuales describen los fundamentos de la formación del color, las características de la interacción de la luz con los tejidos dentales y materiales restauradores, además de los principales métodos de selección y reproducción de color en la odontología estética.

\section{PALABRAS CLAVE}

La visión del color; Chroma; Valor; Matiz; Luz; Odontología Estética. 
INTRODUCTION

Restorations with natural appearance are the main goal of aesthetic treatments. However, the study of color is still absent from the curriculum of most dental schools on the planet $(1,3)$. Thus, in different specialties, professionals perform the procedure of color selection and reproduction empirically, subject to the same frustrations and disappointments of previous generations.

In a contrary manner to popular belief, the color is not a static attribute inherent to objects. It is a brain response to an electromagnetic stimulus sensitive to our eyes. For the existence of color, it is necessary the presence and interaction of three undamental and interdependent factors: the light source, the object and the observer (Fig. 1). After being emitted by a source and intercepted by an object, the light energy can be reflected or transmitted to the eyes of the observer, responsible for capturing and transformation of this physical energy into nerve impulses that are interpreted by the brain as a chromatic sensation $(3,6)$. The need for brain interpretation, however, gives to the visual method of observation a complex and subjective character, even before the standardization of the light source and the observer, as described in several studies in the literature $(2,7,8)$.

Fortunately, knowing the science of color is not essential for it observation and appreciation. The effects of an orange sunset, for example, can be seen and appreciated by all individuals, even those who do not understand how they are formed. However, when we want control and predictability, as it happens in esthetic restorative treatments, such knowledge is essential. In other words, it has become imperative to know the optical phenomena that determine the chromatic expression of natural teeth and their clinical application for obtaining success in aesthetic treatments (9).

\section{LIGHT SOURCE}

The light source plays a major role in the chromatic procedures. The same object when viewed from different sources may have different colors for each of the sources $(3,6)$. Therefore, it becomes extremely necessary for the dentist and the laboratory team use proper lighting.

Light is a form of electromagnetic energy, distinct from radio waves or microwaves by the wavelength. Although the human eye is constantly exposed to all wavelengths of the electromagnetic field, only a small range between $380 \mathrm{~nm}$ and 700 $\mathrm{nm}$, called the visible spectrum, is able to stimulate photosensitive retinal cells, triggering the process of color perception (Fig. 2) $(3,6)$.

Sunlight, also called natural light or white light, contains all the colors of the visible spectrum as evidenced by Isaac Newton (1730), when dissociated a beam of white light into seven colors by a prism interception (10). This luminous quality plays a key role in the science of colors and for this reason should be considered the first choice in chromatic procedures. When this option is not possible, is highly recommended to use lamps that simulate solar lighting in ideal weather conditions.

According to the international commission of illuminating (CIE, Commission Internationale de L'eclairage) there are several light sources and each one has its color temperature characteristic described in Kelvin degrees (K) (11). However, illuminants with a temperature of $2856 \mathrm{~K}$ (standard A) and with a temperature of $6500 \mathrm{~K}$ (standard D), are the most commonly found in supermarkets and specialized stores, and can be considered basic sources (Fig. 3) (12, 13).

The illuminants "standard A" presents yellow chromatic trend that resembles a candle flame and 


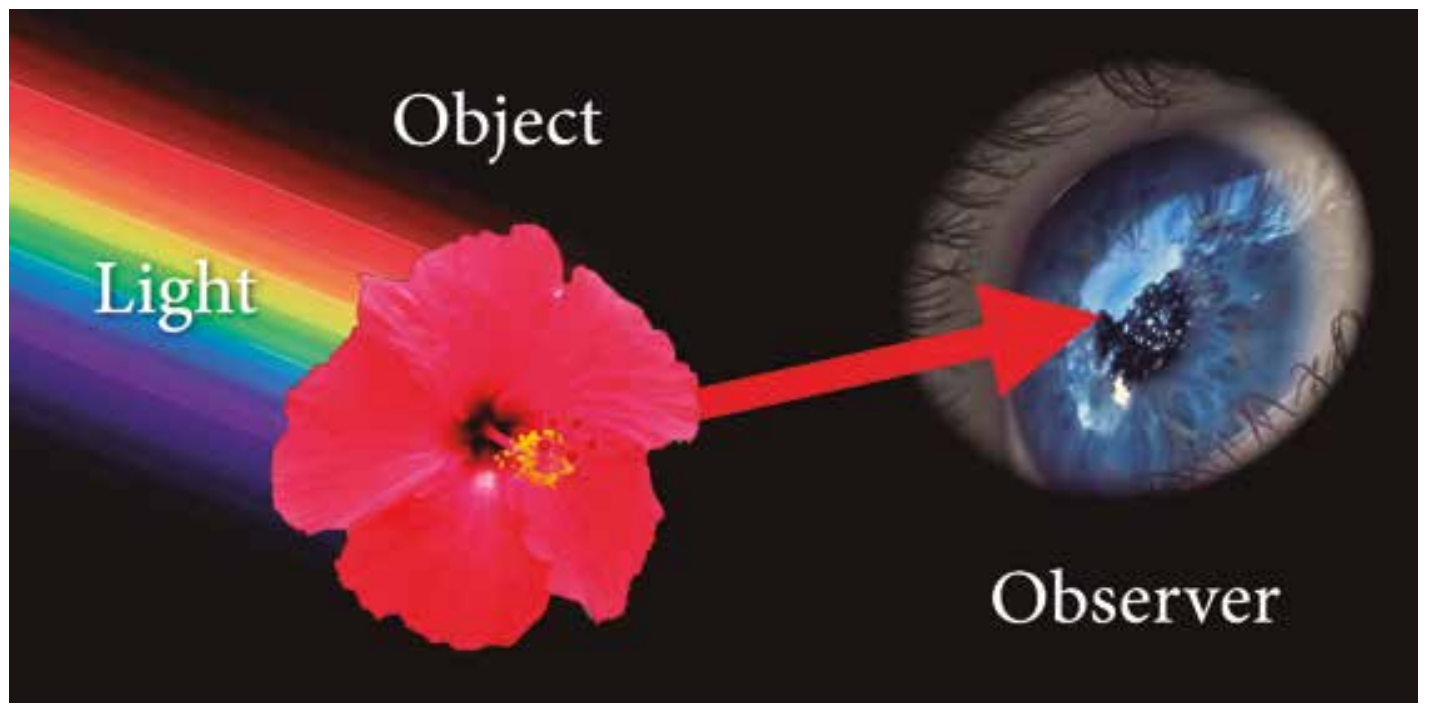

Figure 1. For the existence of color, it is necessary the presence and interaction of three fundamental and interdependent factors: the light source, the object and the observer.

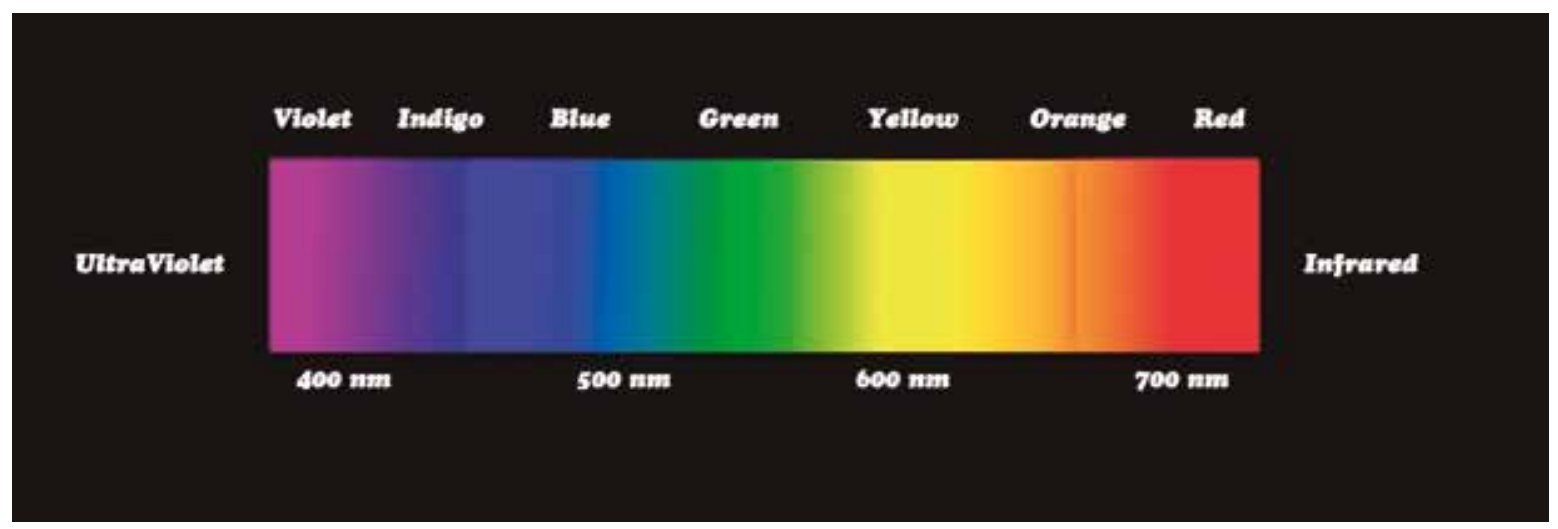

Figure 2. Although the human eye is constantly exposed to all wavelengths of the electromagnetic field, only a small range between 380 $\mathrm{nm}$ and $700 \mathrm{~nm}$, called the visible spectrum, is able to stimulate photosensitive retinal cells, triggering the process of color perception.

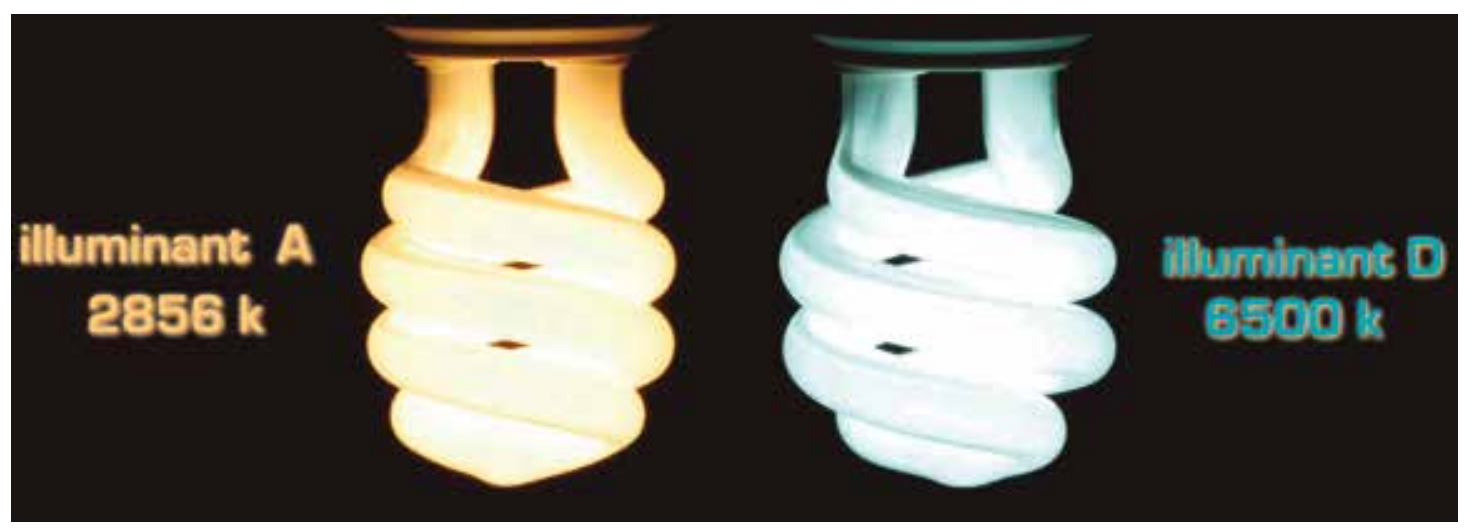

Figure 3. Illuminants with a temperature of $2856 \mathrm{~K}$ (standard $\mathrm{A}$ ) and with a temperature of $6500 \mathrm{~K}$ (standard D), are the most commonly found in supermarkets and specialized stores, and can be considered basic sources. 
for this reason are called incandescent. Because the sum of the wavelengths of the light spectrum represents its color temperature, they exhibit low spectral amplitude and should not be used alone in chromatic procedure. However, the illuminant "standard D" presents a bluish chromatic trend, higher spectral amplitude and ultraviolet (UV) wavelength included, being called fluorescent. Indeed, the light spectrum emitted by them closely resembles natural daylight and, therefore, should be considered the first option when you can't use it $(3,5)$.

Since being established spectral quality, other major factor related to the light source is the intensity that the energy reaches our eyes. Likewise a high luminous intensity obliterates details for correct chromatic evaluation, insufficient intensity hinders its discernment. The ideal intensity can be measured with the aid of light meter (Fig. 4) and must remain near to 100 candles $(3,5,14)$. Such intensity is responsible for promoting an proper aperture of the pupilar diameter, a crucial factor in the selection and accurate color reproduction and usually equates to a unit with four fluorescent lamps of 220 watts disposed 2 meters away from the operative field $(5,14)$.

\section{HOW LIGHT REVEALS THE COLOR OF OBJECTS?}

When light strikes the surface of an object, different wavelengths can be absorbed, reflected (in a specular or diffuse) or transmitted. The light that is not absorbed determines the wavelength that can be observed (the color of the object). The specular reflection is that which occurs just like the surface of a mirror. In this type of reflection the reflected light has the same angle of the incident light. In diffuse reflection, the reflected light has several directions. Finally, the transmitted light is that which penetrates and passes through the material (Fig. 5) (15).
When the light is intercepted by an opaque object, basically, it is reflected and absorbed on the surface of the object. When the light stops being transmitted through the air to be transmitted through translucent objects, there is the change of direction of the light path, phenomenon known as refraction (16). It occurs due to the difference in the speed of light transmission between the media and can be quantified by the calculation of refractive index, which is the ratio of the speed transmission of light in vacuum to the speed transmission of light in the object (17). The difference in refractive index between two materials determines the deviation of the light path in the interface.

Generally, the refractive index is smaller in the lower wavelengths, in other words, the red light is faster than the blue light in the same material. For this reason, the lower wavelengths suffer greater deviation than the longer wavelengths. The variation of refractive index as a function of wavelength is called dispersion (16).

Inside of the object, the dispersion is repeated whenever light is intercepted by a new interface. The presence of a large number of internal particles increases the amount of interfaces and reduces the light transmission (15, 16, 19). Besides the quantity, size and shape of the particles also influences the scattering of light. When the particle size corresponds to the size of the wavelength of blue light, only the wavelength of equal size or smaller than blue (violet, indigo and blue) will be refracted by these particles while longer wavelengths will be transmitted normally.

A red object has this characteristic because of its ability to reflect the red wavelength while transmitting others. An object that reflects blue and red wavelengths has a chromatic appearance perceived in magenta, result of the combination of those two colors reflected. Thus, if the object 
absorbs the entire incident light, there is no reflection and then we will see a dark or black color. If the object reflects fully white incident light, our vision will identify a white object.

Thus, if some energy is absorbed and part is reflected, the display is a colored object $(3,5)$.

\section{COLOR DIMENSIONS}

In order to provide more objectivity for the chromatic communication, for nearly a century, the literature discussed and gave support to the three-dimensional color classification, proposed in 1898, by the american artist Albert Munsell. In this system colors can be expressed through the interaction of three dimensions called hue, chroma and value $(1,3)$.

HUE

Hue is the dimension of color easier to recognize as it corresponds to the actual name of the color. It is the quality that distinguishes one amily of color from another, i.e., red to green or blue to yellow. Hue is also described as the main wavelength reflected by the interaction of light energy and the object. In dentistry is considered the least chromatic dimension due to small variation between the dental hues, which are generally limited to variations between shades of yellow and orange (Fig. 6) (1, 3, 15, 19).

\section{CHROMA}

Chroma is the degree of saturation, intensity, purity or quantity of a specific pigment shade, making it impossible to compare this dimension between different hues. In translucent objects chroma is strongly influenced by the thickness of the material. In natural teeth it can vary from one tooth to another and between regions of the same tooth (Fig. 7) $(1,3,15,19)$.

\section{VALUE}

The value is the dimension of color more easily identifiable and represents the reflected light from the object. The value range is limited at its upper end by white color (high value) that represents the lightest color possible and at its lower end by the black color (low value), which represents the lowest luminosity that color can provide. Between these extremes stretches an achromatic scale consisted of different shades of gray $(1,3,15,19)$. When considering the selection and reproduction of colors in dentistry, the value is the more important dimension, since the small differences in the amount of value are more easily identified than the small differences in hue and chroma (Fig. 8) (20).

\section{HOW COLORS ARE COMBINED?}

A fundamental aspect to understand how new colors are formed from other pre-existing, is related to the knowledge of synthesis that occurs in both light and pigments $(3,5)$. By mixing any two spectral colors, we will be conducting an additive synthesis, because each color added is a fraction of the white color. In practice there are three primary colors: red, green and blue. From these colors all other can be formed. This system is identified by the acronym RGB (red, green and blue) is used in the formation of images of televisions, cameras and computer monitors (Fig. 9). When stratifying restorations, however, the clinician does not mix different types of light but a quantity of pigments capable of absorbing fractions of incident light while reflecting others. By the fact this synthesis is 
caused by the absorption of certain wavelengths, it is known as subtractive (Fig. 10).

METAMERISM

The color reproduction of the tooth with restorative material is possible only due to the phenomenon called metamerism, observed when objects that have different physicochemical characteristics interact similarly with light energy resulting in equal chromatic appearance $(12,13)$. These objects are called metameric pairs (21). In aesthetic dentistry, the search for metameric pair formation is imperative when trying to reproduce the color of the tooth using restorative material. Despite the various treatment techniques performed by direct or indirect method, there are situations that can cause the chromatic differentiation of metameric pairs and the aesthetic failure of treatment. Called "metameric failure", these situations can be noted in the object or the observer (5).

Metameric failures manifested on the object, which usually occur after making restoration, are generally associated with changes in light source $(3,5,21)$. A common mistake is to perform the procedure of selection and color reproduction under halogen light reflector. In this condition the restoration can seamlessly blend into the tooth, (12) or repair of ceramic restoration can be perfectly realized with the use of composite resin, (13) but in a richer light source (natural light for example), different interactions can occur between light , the tooth and the restorative material, resulting in perception of different colors. To avoid this situation, as described before, the color selection and reproduction procedures require lamps presenting a broad and balanced light spectrum, simulating the natural light in ideal conditions (Fig. 12).

Metameric failures manifested in the observer can occur when the illuminating source and the object keeps constant with different observers. It is a result of the complex psycho physiological mechanism, beginning with the eye capture and the brain interpretation of each viewer $(14,21)$. Thus, the color of a restoration may be satisfactory for the professional and patient and unsatisfactory to their relatives and friends. The solution to this problem is viable but costly. An alternative is to use electronic devices for color selection. As we shall see later, the instrumental method of observation is an important aid for professionals of all levels, although these instruments do not guarantee that metameric failure manifested in the observer no longer occurs because the subjectivity of the final color is always performed by the visual method. At the end of treatment, despite the excellent aesthetics, the patient may be instructed as to the eventual manifestation of small metameric failure due to inability to completely reproduce the same interaction devices using different materials $(14,21)$.

\section{CONCLUSION}

In this first article, we demonstrate the great importance of the light source in the chromatic procedures. We saw how the objects modify the light and the different resulting types of interactions. Therefore, we want to highlight the extreme importance for the dentistand the laboratory team to use proper lighting to obtain naturallooking results. In the second article of this trilogy, we will focus in the interaction of light with dental tissues and its color results. 

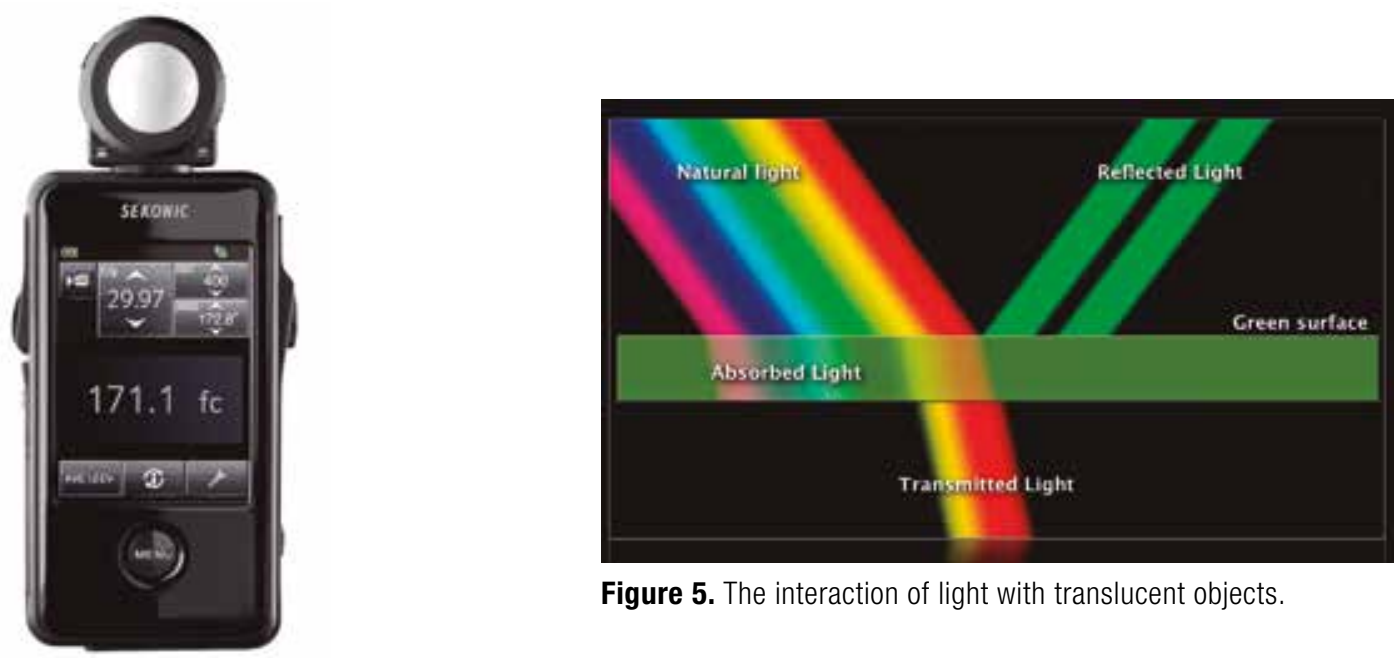

Figure 5. The interaction of light with translucent objects.

Figure 4. The ideal light intensity can be measured with the aid of light meter.

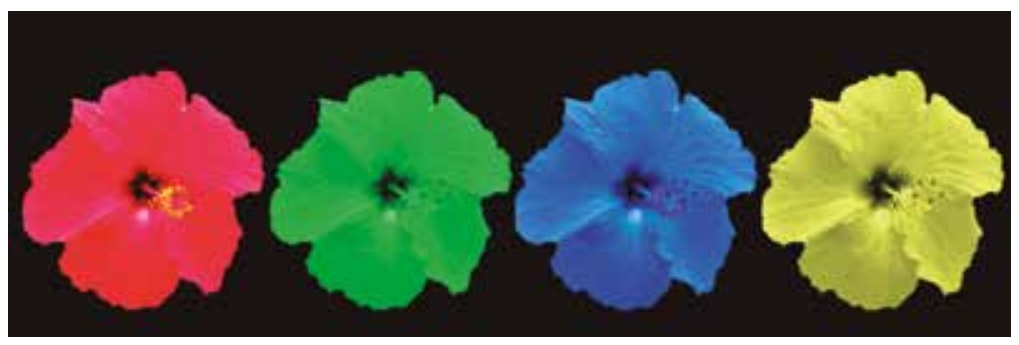

Figure 6. Hue.

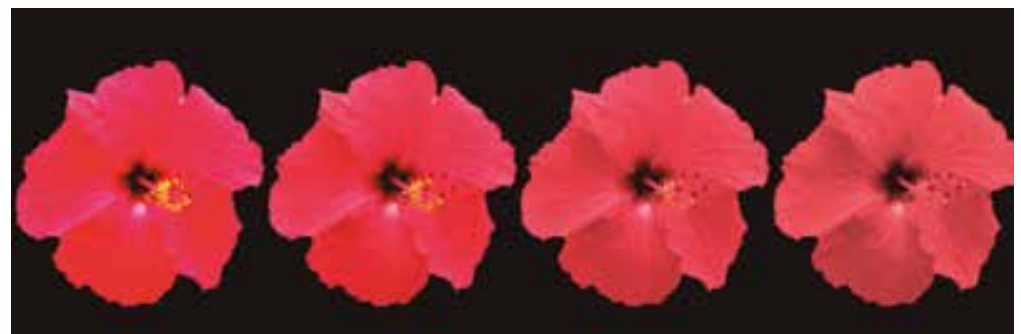

Figure 7. Chroma.

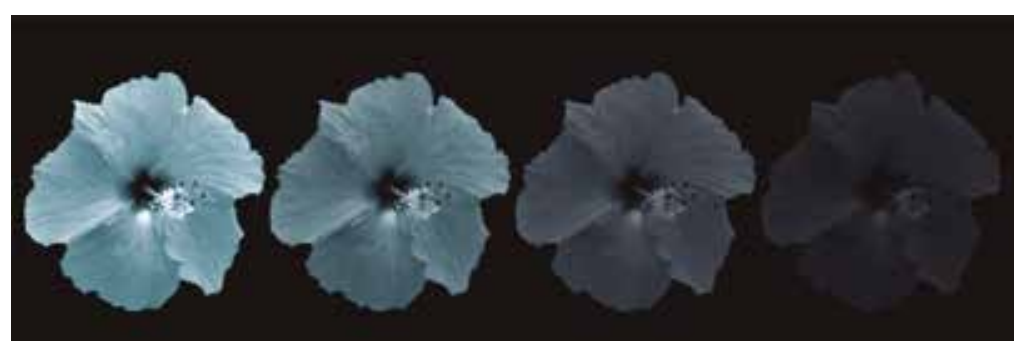

Figure 8. Value. 


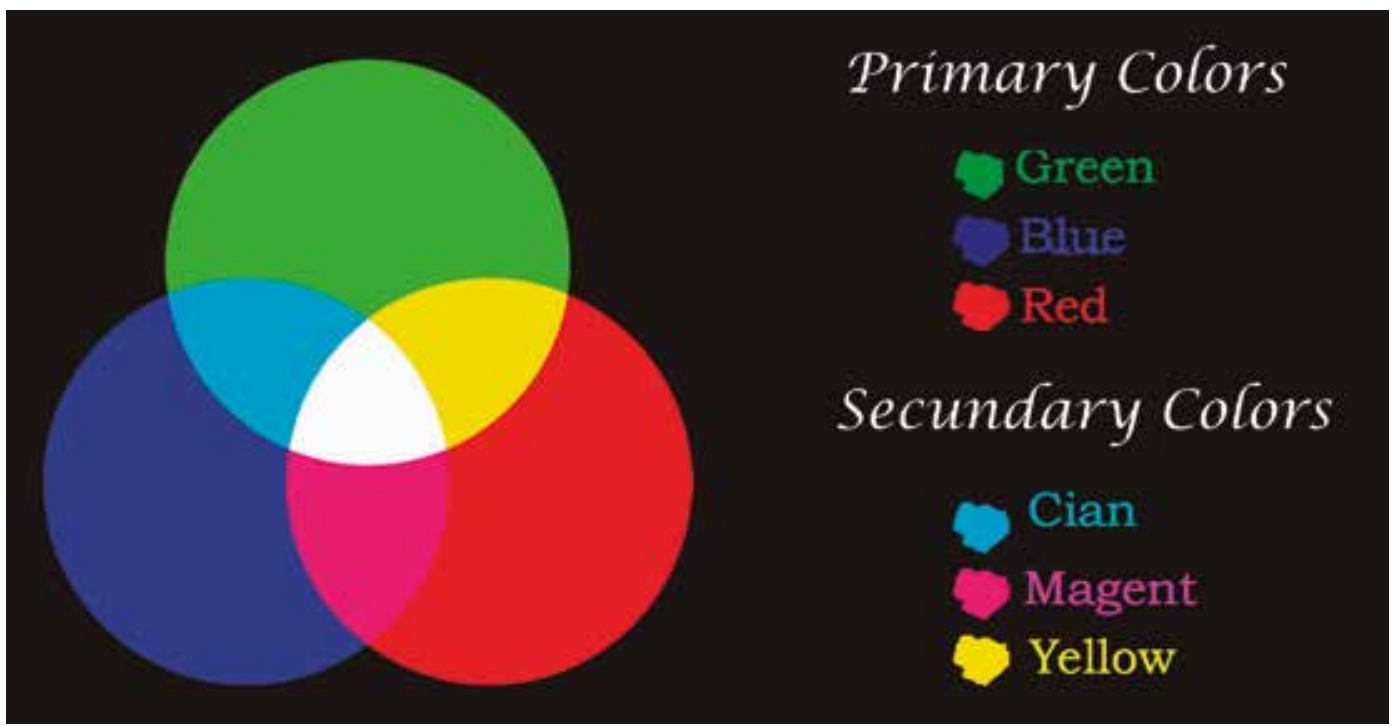

Figure 9. Additive synthesis.
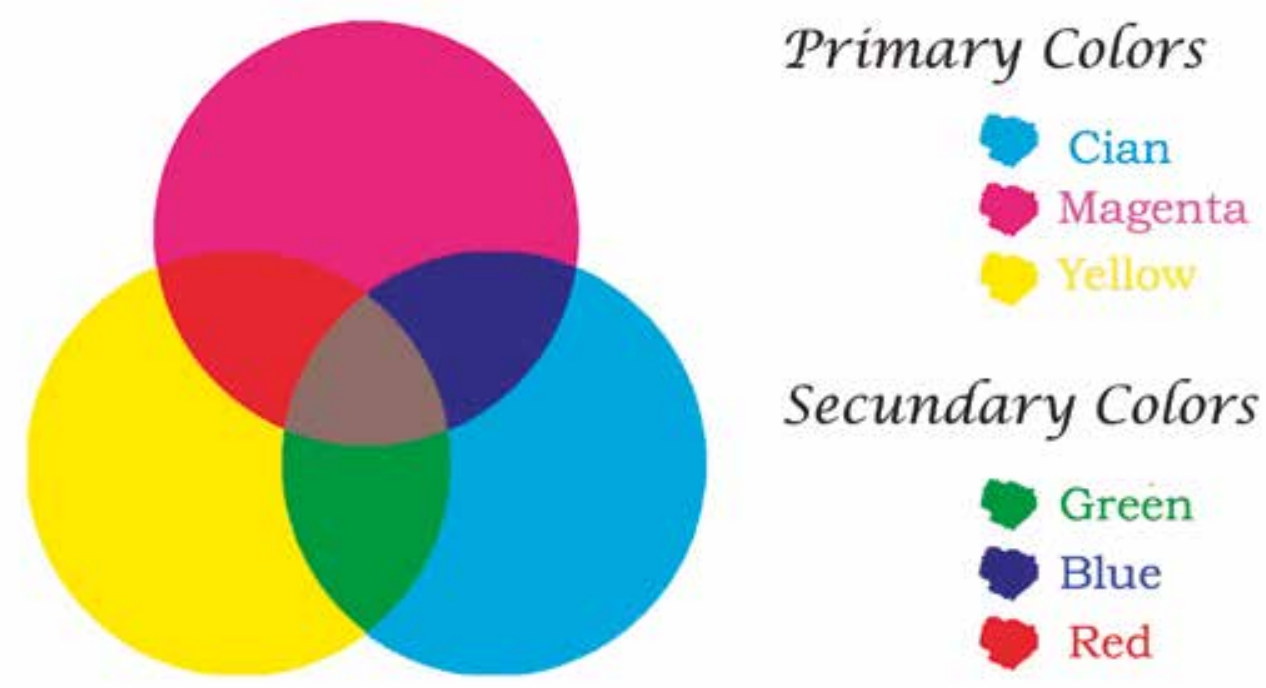

Figure 10. Subtractive Syntesis. 


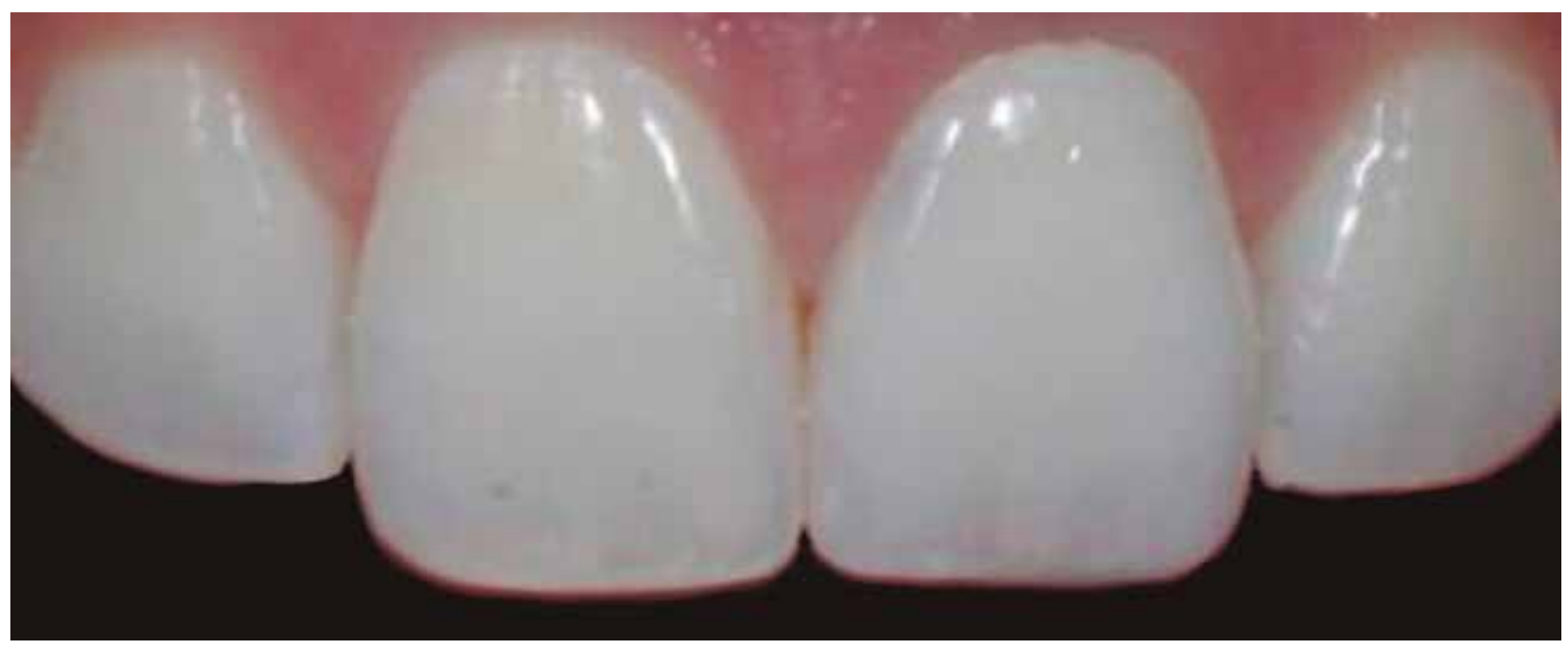

Figure 11. Patient, with ceramic veneer on tooth 21 , observed under illuminant type A (2856 K). We can see the yellowish hue all over the image and great color resemblance between the natural tooth (adjacent) and the restored tooth.

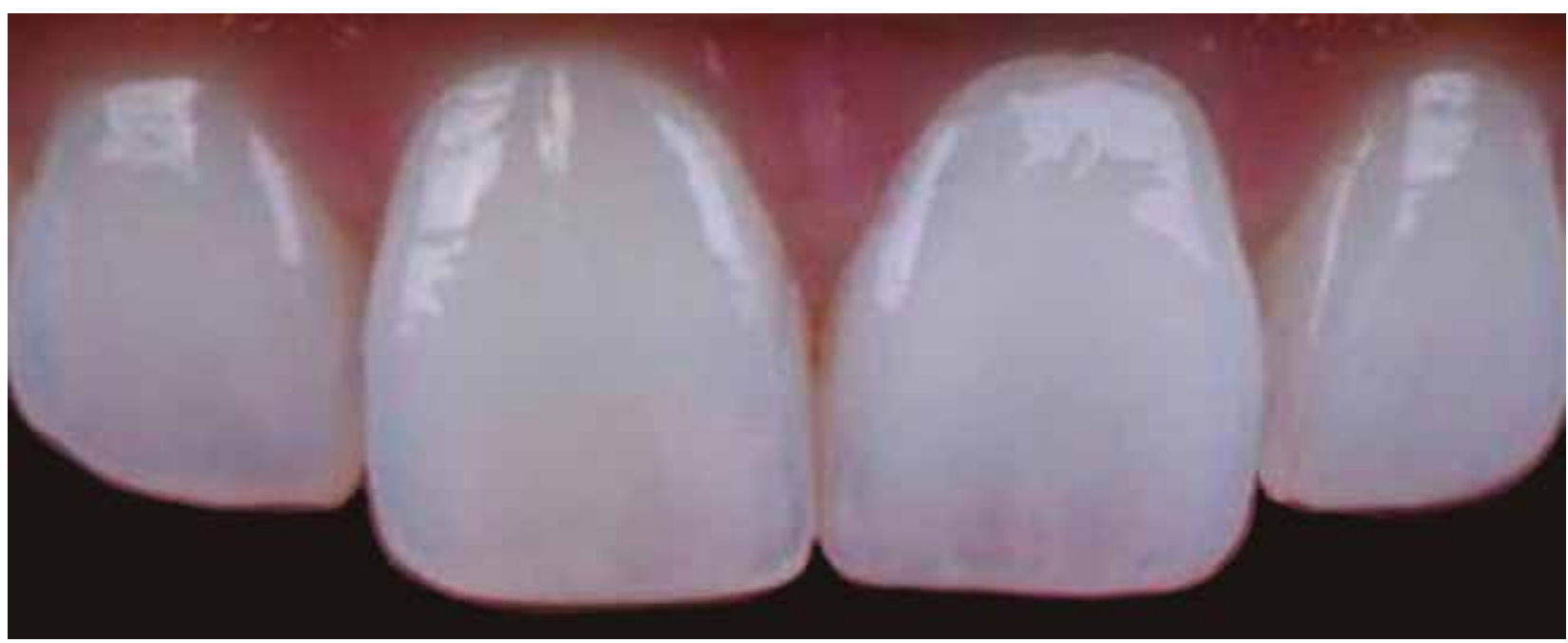

Figure 12. The same patient, when observed under the D type illuminating (from 6500k), presents more clear and natural teeth. We can detect the increase in dental nuances due to an increase in the quality of the light spectrum. Note that with a richer source of light, a small difference in the value of the central incisors can also be noted. 


\section{REFERENCES}

1. Sproull R. C. Color matching in dentistry. Part 1. J. Prosthet Dent 1973; 29(4): 417-423.

2. Chu S. J., Tarnow D. P. Digital shade analysis and verification: a case report and discussion. Pract Proced Aesthet Dent 2001; 13(2): 129-136.

3. Chu S. J., Devigus A., Mieleszko A. J. Shade matching and communication in esthetic dentistry. Chicago: Quintessence, 2004.

4. Ahmad I. Three dimension shade analysis: perspectives of color-part 1. Pract Period Aesthet Dent 1999; 11(7): 557-564.

5. Billmeyer and Saltzman's principles of color technology. 3rded. New York: John WileySons; 2000.

6. Joiner A. Tooth colour: a review of the literature. J Dent 2004; Suppl(1): 3-12.

7. Okubo S. R. et al. Evaluation of visual and instrumental shade matching. J. Prosthet. Dent 1998; 80(6): 642-648.

8. Paul S. et al. Visual and spectrophotometric shade of human teeth. J Dent Res 2002; 81(8): 578-582.

9. Vanini L. Light and color in anterior composite restorations. Pract Periodontics Aesthet Dent 1996; 8(7): 673-682.

10. Newton I. Optiks. London, England: Innys; 1730.

11. Comission Internationale de L'Eclairage. Colorimetry, official recommendations of the international commission on illumination. Paris: Bureau Central de La CIE. Publication CIE No. 15 (E1.3.1), 1971.

12. Lee Y. K., Powers, J. M. Metameric effect between resin composite and dentin. Dent Mater. 2005; 21(10): 971-6.
13. Kim S. H., Lee, Y. K. Lim B. S., Rhee S. H., Yang Y. C. Metameric effect between dental porcelain and porcelain repairing resin composite. Dent mater. 2007; 23(3): 374-9.

14. Ahmad I. Three-dimensional shade analysis: perspectives of color-part 2. Pract Proced Aesthet Dent 2000; 12(6): 557-564.

15. Schmeling M., de Andrada MAC, Maia H.P., Araújo EM. Translucency of value resin composites used to replace enamel in stratified composite restoration techniques. J Esthet Restor Dent 2012; 24(1): 53-58.

16. Primus C. M., Chu CCY, Shelby J. E., Buldrini; Helcle C. E. Opalescence of dental porcelains enamels. Quintessence International 2002; 33(6): 439-449.

17. Wyszecki G., Stiles W. S. Color science. Concepts and methods, quantitative data and formulae. 2nd ed. New York: 2000.

18. Lee Y. K. Influence of scattering/ absorption characteristics on the color of resin composites. Dent Mater 2007; 23(1): 124-31.

19. Schmeling M., Meyer-Filho A., de Andrada MAC, Baratieri L. N.

20. Chromatic influence of value resin composites. Oper Dent 2010; 35(1): 45-9.

21. Yamamoto $M$. The value conversion system and a new concept for expressing the shades of natural teeth. Quintessence Dent Technol 1992; 19: 9.

22. Allen E. Some new advances in study of metamerism. Color Engineering. 1969; 7(1): $35-40$.

\section{Max Schmeling DDS, MS, PhD'1}

1. Federal University of Santa Catarina (UFSC), Brazil. Collaborator Professor of Federal University of Santa Catarina (UFSC), Brazil. Head of Operative Dentistry Department of Central Dental Clinics of Brazilian Army -

OCEx, Rio de Janeiro, Brazil.

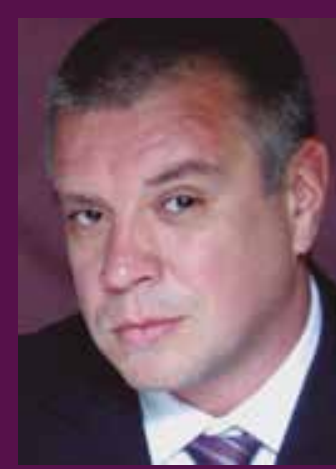

